\title{
Fujian cypress and two other threatened tree species in three conservation zones of a nature reserve in north-western Vietnam
}

\author{
Thi Hoa Hong Dao ${ }^{1,2^{*}}$ and Dirk Hölscher ${ }^{1}$
}

\begin{abstract}
Background: Fujian cypress (Fokienia hodginsii) is a highly valued but endangered tree species. The Ta Xua Nature Reserve in Vietnam is one of its main conservation centers. This nature reserve consists of a fully protected core zone, a buffer zone in which low intensity forest use is permitted, and a forest restoration zone in which forest regenerates after shifting cultivation.

Methods: The community and population status of F. hodginsii and two other threatened tree species (Aglaia spectabilis and Quercus platycalyx) were assessed across the three conservation zones. Based on 120 random sample plots of $400 \mathrm{~m}^{2}$, we applied adaptive cluster sampling for trees with a diameter at breast height (DBH) of at least $6 \mathrm{~cm}$. In addition, tree regeneration $(\mathrm{DBH}<6 \mathrm{~cm})$ was assessed.

Results: In the core zone, F. hodginsii, A. spectabilis and Q. platycalyx occurred at moderate densities (4.9, 5.1 and 4.4 trees.ha ${ }^{-1}$, respectively). F. hodginsii and A. spectabilis were however much less abundant in the buffer and restoration zones. In contrast, $Q$. platycalyx had its highest density in the restoration zone. Regeneration of all three target species occurred in the core zone; however, there were only a few regenerating trees of $F$. hodginsii and $A$. spectabilis in the buffer and regeneration zones. Regeneration of $F$. hodginsii and A. spectabilis was mostly in the vicinity of conspecific adult trees.

Conclusions: F. hodginsii and A. spectabilis were mostly confined to the core zone, and regeneration of these species was rare in the buffer and restoration zones. For these two species, the core zone was the most important refuge, so continued conservation of this zone is important for the preservation of these species. The results of this study in the Ta Xua Nature Reserve do not confirm the classification of Q. platycalyx as 'vulnerable' in the Vietnam Red List. Further forest monitoring including repeated population assessments is needed to evaluate the vulnerability of threatened tree species.
\end{abstract}

Keywords: Abundance, Adaptive cluster sampling, Conservation, Rarity, Secondary forest, Tropical forest

\section{Background}

The high diversity of tree species in tropical forests is driven by a large proportion of rare species (Hubbell 2013; ter Steege et al. 2013). Rare species are vulnerable and threatened to extirpation and extinction when their habitats are destroyed (Gaston 1994; Laurance 1999; Sodhi et al. 2004; Hubbell 2013). In recent decades,

\footnotetext{
*Correspondence: tdao@gwdg.de

${ }^{1}$ Tropical Silviculture and Forest Ecology, Faculty of Forest Sciences and Forest Ecology, Georg-August-Universität Göttingen, Büsgenweg 1, 37077 Göttingen, Germany

${ }^{2}$ Forest Inventory and Planning, Faculty of Silviculture, Vietnam National University of Forestry, Hanoi, Vietnam
}

extensive conversion and degradation have significantly affected tropical forests (Dirzo and Raven 2003; Sodhi et al. 2009; Gibson et al. 2011). Southeast Asia has high rates of deforestation, and this has endangered many plant and animal species and led to local extinctions (Sodhi et al. 2004). Selective logging may convert a common forest tree species into a rare one, and cause local extirpation or even extinction of rare and high-value species (Fearnside 1997; Laurance 1999). Thus, there is a need for conservation in tropical forests and one focus should be on rare and threatened species (Philippi 2005; Hubbell 2013).
Springer Open

(c) The Author(s). 2017 Open Access This article is distributed under the terms of the Creative Commons Attribution 4.0 International License (http://creativecommons.org/licenses/by/4.0/), which permits unrestricted use, distribution, and reproduction in any medium, provided you give appropriate credit to the original author(s) and the source, provide a link to the Creative Commons license, and indicate if changes were made. 
A major forest conservation strategy involves the establishment of strictly protected zones to safeguard remaining habitats and species (Bruner et al. 2001; Joppa and Pfaff 2010). These zones are often surrounded by low-use buffer zones, which enhance the conservation value of the protected area and provide forest products for the local population (DeFries et al. 2005; Chape et al. 2005). Primary forests are considered irreplaceable for maintaining tropical biodiversity (Gibson et al. 2011), and strictly protected core zones can be refuges for rare and red-listed tree species. However, protected areas may serve as 'conservation islands' in a sea of 'degraded habitats' (Williams et al. 2000). In the buffer zones, where logging is permitted, the method and intensity of logging can impact species composition in various ways. Low-intensity selective logging may have little detrimental effect on biodiversity (Gibson et al. 2011); however intensive logging can reduce species diversity and exacerbate species loss (Sodhi et al. 2010). Hence, studies of tree communities in different forest conservation zones are essential to evaluate the effectiveness of different conservation practices.

Vietnam has a high biodiversity because of its tropical climate and complex terrain (Facelli and Pickett 1991; Thai 1998). However, wars and over-exploitation have severely degraded the natural forests of Vietnam. Consequently, many species in Vietnam are classified as endangered (Nguyen 2000). In particular, the Vietnam Red List considers 464 plant species as being endangered to different degrees (Nguyen et al. 2007).

Fokienia hodginsii (Dunn) A. Henry \& H.H. Thomas (Fujian cypress) is an iconic tree species in the family Cupressaceae. In Vietnam, the timber of this species is much valued for its use in construction, art works, and furniture because of its characteristic aroma and exceptional wood density. Local people are using its timber in construction through necessity, and rich people use it as the timber of choice. F. hodginsii timber is also exported to Europe and elsewhere in Asia (Osborn 2004). Therefore, intensive logging of $F$. hodginsii has led to a severe decline of its population (Nguyen 2000). This species is now rare, and mainly occurs in certain protected areas (Thomas and Yang 2013). F. hodginsii is listed as 'endangered' in the Vietnam Red List (Nguyen et al. 2007) and as 'vulnerable' in the IUCN Red List (IUCN 2014). Two other threatened tree species in Vietnam are Aglaia spectabilis (Miq.) S.S. Jain \& S.S.R. Bennet and Quercus platycalyx Hickel \& A. Camus. The timber of these two species is of good quality, highly valued and used for construction and furniture. Populations of A. spectabilis and $Q$. platycalyx are seriously fragmented due to habitat destruction and over-exploitation, and both species are listed as 'vulnerable' in the Vietnam Red List (Nguyen et al. 2007).

The Ta Xua Nature Reserve is one of the main conservation centers of $F$. hodginsii in north-western Vietnam. In previous surveys based on random sampling, we found that red-list status and large diameter were predictors of rarity (Dao et al. 2016). However, rare and moderately rare species may not be well represented in random sampling, because such species may be absent in many sampling units, causing errors in the estimates of population sizes (Cochran 1977; Gaston 1994). In such cases adaptive cluster sampling (ACS) can be an effective sampling method (Thompson 1990; Philippi 2005). Therefore, we applied ACS to determine the population status of $F$. hodginsii, A. spectabilis and Q. platycalyx in the Ta Xua Nature Reserve. The reserve consists of a fully protected core zone, a buffer zone in which low intensity forest use is permitted, and a forest restoration zone in which forest regenerates after shifting cultivation. The objectives of this study were to assess tree communities and the abundance of $F$. hodginsii, A. spectabilis and Q. platycalyx, and to determine the regeneration status of the three target species in the three conservation zones. The results will provide quantitative information about the vulnerability of these species, and may serve to guide conservation efforts. More generally, the results will add to our understanding of the extent to which threatened tree species need protection in core conservation zones, and whether they can tolerate different types of forest use.

\section{Methods}

\section{Study area}

The Ta Xua Nature Reserve $\left(21^{\circ} 13^{\prime}-21^{\circ} 26^{\prime} \mathrm{N}, 104^{\circ} 16\right.$ - $104^{\circ} 46^{\prime}$ E, Fig. 1) was established in 2002. The Nature Reserve has high, steeply sloping mountains rising from $320 \mathrm{~m}$ to $2765 \mathrm{~m}$ a.s.l. The climate is humid-tropical, influenced by the north-easterly monsoon. At the nearest meteorological station (Phu Yen, c. $40 \mathrm{~km}$ from Ta Xua Nature Reserve at $175 \mathrm{~m}$ a.s.l.), the annual precipitation ranges from $1600 \mathrm{~mm}$ to $1900 \mathrm{~mm}$, and the average temperature is $20^{\circ} \mathrm{C}$.

The reserve has a core zone of 15,211 ha which is strictly protected. All human activities, such as logging, hunting, and gathering of non-timber forest products, are prohibited. During our field work, signs of these activities were only rarely observed in the core zone. Forest cover in the core zone is $87 \%$, and forest types range from evergreen and broad-leaved rainforest at lower elevations to coniferous forest mixed with some evergreen and broad-leaved species on the higher peaks (Forest Inventory and Planning 


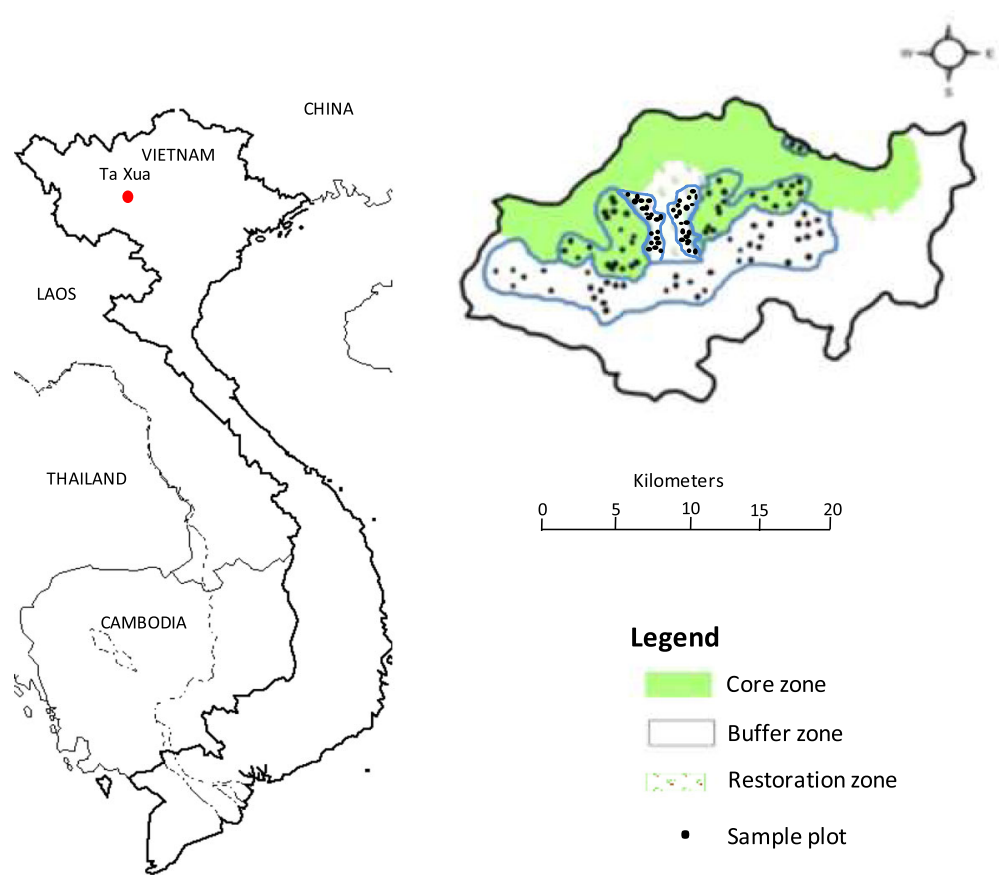

Fig. 1 Location of the Ta Xua Nature Reserve in north-western Vietnam (left), and detail of the study area, which is enclosed by blue lines (right; 1000-1700 $\mathrm{m}$ a.s.l.). Black dots indicate initial random sample plots (40 plots per zone)
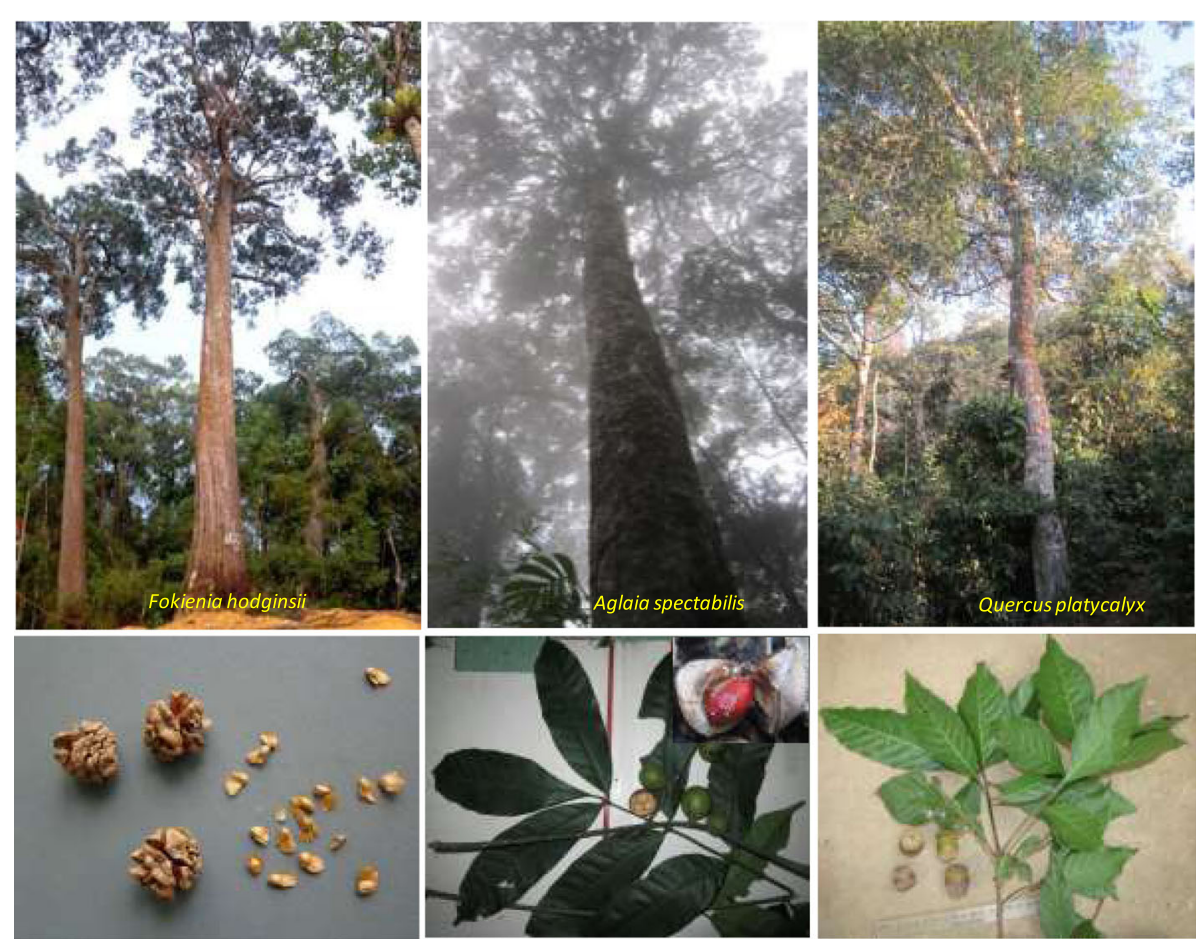

Fig. 2 Mature tree, female cones, and seeds of F. hodginsii (left); mature tree, leaves, fruits and seeds of A. spectabilis (center); and mature tree, leaves, and nuts of Q. platycalyx (right). Photos are from Vuong Duy Hung, Dao Thi Hoa Hong, Truong Tat Do, and Trinh Ngoc Bon 
Table 1 Number of initially positive plots (among the 40 initial random plots per zone), added positive plots, added negative plots (from ACS), and individual trees $\geq 6 \mathrm{~cm}$ of the three target species. Means and standard deviations of DBH and tree density (trees $\geq 6 \mathrm{~cm} \cdot \mathrm{ha}^{-1}$ ) were determined by the Hansen-Hurwitz estimator

\begin{tabular}{|c|c|c|c|c|c|c|c|c|c|}
\hline & \multirow{2}{*}{$\begin{array}{l}\text { Conservation } \\
\text { zone }\end{array}$} & \multirow{2}{*}{$\begin{array}{l}\text { Initial } \\
\text { positive plots }\end{array}$} & \multirow{2}{*}{$\begin{array}{l}\text { Added } \\
\text { positive plots }\end{array}$} & \multirow{2}{*}{$\begin{array}{l}\text { Added } \\
\text { negative plots }\end{array}$} & \multicolumn{3}{|c|}{ Detected individuals (tree $\geq 6 \mathrm{~cm}$ ) } & \multirow{2}{*}{$\begin{array}{l}\text { Density } \\
\left(n \cdot h a^{-1}\right)\end{array}$} & \multirow[t]{2}{*}{$\mathrm{DBH}(\mathrm{cm})$} \\
\hline & & & & & Initial & Added & Total & & \\
\hline \multirow[t]{3}{*}{ F. hodginsii } & Core & 5 & 13 & 31 & 11 & 36 & 47 & $4.9 \pm 2.5$ & $16.9 \pm 11.2$ \\
\hline & Buffer & 2 & 1 & 4 & 4 & 1 & 5 & $1.9 \pm 1.3$ & $29.2 \pm 13.4$ \\
\hline & Restoration & 1 & 0 & 4 & 1 & 0 & 1 & $0.6 \pm 0.6$ & $8.3 \pm N A$ \\
\hline \multirow[t]{3}{*}{ A. spectabilis } & Core & 8 & 37 & 53 & 12 & 62 & 74 & $5.1 \pm 2.2$ & $17.3 \pm 10.1$ \\
\hline & Buffer & 1 & 0 & 4 & 1 & 0 & 1 & $0.6 \pm 0.6$ & $12.7 \pm N A$ \\
\hline & Restoration & 1 & 1 & 6 & 1 & 1 & 2 & $0.6 \pm 0.6$ & $16.6 \pm 14.4$ \\
\hline \multirow[t]{3}{*}{ Q. platycalyx } & Core & 7 & 6 & 38 & 7 & 6 & 13 & $4.4 \pm 1.2$ & $27.8 \pm 18.8$ \\
\hline & Buffer & 6 & 8 & 31 & 7 & 11 & 18 & $4.9 \pm 2$ & $22.4 \pm 15.3$ \\
\hline & Restoration & 4 & 1 & 18 & 29 & 1 & 30 & $16.6 \pm 8$ & $17.3 \pm 5.5$ \\
\hline
\end{tabular}

NA not available

Institute (FIPI), 2002). The core zone can only be reached by footpaths. These paths were either created before the nature reserve had been established, or were established to facilitate ranger patrols, research activities, or access for tourists.

The buffer zone encompasses 24,674 ha above $900 \mathrm{~m}$ a.s.l. and has $44 \%$ forest cover. The zone is managed by the H'Mong people in accordance with forest management regulations that were established by the law of forest protection and development (Law No.29/2004/QH 11, 2004). Based on these regulations, a maximum of 25 trees may be felled per year in a forest area of 10,856 ha. However, during field work, signs of illegal tree felling were observed. Land below $900 \mathrm{~m}$ a.s.l. is mainly agricultural land, with upland rice, maize, and sugarcane predominating (Forest Inventory and Planning Institute (FIPI), 2002).

A protected restoration zone was also established within the reserve, consisting of 2439 ha enclosed within the core zone, and partly bordering on the buffer zone. In the past, the H'Mong people lived there and practiced shifting cultivation, but this area has been subject to statutory protection since 2002 (Forest Inventory and Planning Institute (FIPI), 2002).

\section{Target tree species}

Three tree species (Fokienia hodginsii (Dunn) A. Henry \& H.H. Thomas (Fujian cypress), Aglaia spectabilis (Miq.) S.S. Jain \& S.S.R. Bennet, and Quercus platycalyx Hickel \& A. Camus; Fig. 2), were surveyed in this study.

Table 2 Site conditions and forest structural characteristics of the three conservation zones. Numbers are means and standard deviations, with 40 initial random plots per zone

\begin{tabular}{|c|c|c|c|}
\hline & Core zone & Buffer zone & Restoration zone \\
\hline Total study area (ha) & 72.8 & 115.1 & 21.6 \\
\hline Elevation (m a.s.l.) & $1449.1 \pm 62.6^{a}$ & $1363.3 \pm 86.7^{b}$ & $1465.5 \pm 91.0^{\mathrm{a}}$ \\
\hline Slope inclination (degrees) & $39.5 \pm 7.7^{a}$ & $35.9 \pm 5.4^{b}$ & $35.6 \pm 5.9^{b}$ \\
\hline Soil pH & $4.7 \pm 0.4^{a}$ & $4.7 \pm 0.4^{a}$ & $4.8 \pm 0.2^{a}$ \\
\hline 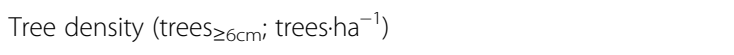 & $925 \pm 251^{a}$ & $1006 \pm 357^{a}$ & $1660 \pm 387^{b}$ \\
\hline $\mathrm{DBH}\left(\right.$ trees $\left._{\geq 6 \mathrm{~cm}} ; \mathrm{cm}\right)$ & $21.4 \pm 3.4^{a}$ & $16.6 \pm 3.0^{b}$ & $12.8 \pm 1.4^{c}$ \\
\hline Basal area $\left(\right.$ trees $\geq 6 \mathrm{~cm} ; \mathrm{m}^{2} \cdot \mathrm{ha}^{-1}$ ) & $52.9 \pm 21.4^{\mathrm{a}}$ & $30.4 \pm 15.4^{b}$ & $24.8 \pm 5.9^{c}$ \\
\hline Canopy closure (\%) & $88.4 \pm 7.2^{a}$ & $84.5 \pm 9.4^{b}$ & $81.3 \pm 6.4^{c}$ \\
\hline Observed species richness (trees $\geq 6 \mathrm{~cm}, \mathrm{sp}$. per 40 plots) & 193 & 173 & 135 \\
\hline Mean species richness (trees $\geq 6 \mathrm{~cm}$, sp. per plot) & $22.1 \pm 5.1^{a}$ & $19.3 \pm 5.9^{b}$ & $16.8 \pm 5.0^{c}$ \\
\hline Observed red-listed species richness (trees $\geq 6 \mathrm{~cm}$, sp. per 40 plots) & 16 & 10 & 5 \\
\hline Stumps (no. per plot) & $0.6 \pm 0.8^{a}$ & $1.6 \pm 1.6^{b}$ & $1.7 \pm 1.4^{b}$ \\
\hline Footpaths (no. per plot) & $0.9 \pm 0.6^{\mathrm{a}}$ & $1.5 \pm 0.8^{b}$ & $1.1 \pm 0.9^{\mathrm{a}, \mathrm{b}}$ \\
\hline
\end{tabular}

Significant differences in the means of three conservation zones at the level of $p \leq 0.05$ were indicated in different superscript letters 
F. hodginsii is native to southern, south-western and south-eastern China (Chongqing, Fujian, Guangdong, Guangxi, Guizhou, Hunan, Jiangxi, Sichuan, Yunnan, Zhejiang), Lao People's Democratic Republic and Vietnam (IUCN 2014). It usually occurs above $900 \mathrm{~m}$ a.s.l. and grows on acidic and well-drained soils. It is a slow-growing, long-lived, large tree and is considered a late successional species (Nguyen et al. 1996; Le and Le 2000).

A. spectabilis has a wide distribution, and occurs in Southeast Asia, China, and India. It is usually found in near natural or slightly disturbed forests and grows on deep, clay and well-drained soil. The tree species is longlived, reaching great size. Seeds are dispersed by mammals (especially civets and squirrels), birds, or ballistic dehiscence (Nguyen et al. 1996). The natural population is fragmented due to habitat destruction and over-exploitation.

Q. platycalyx is native to Vietnam and China, and occurs in secondary forests (Nguyen et al. 1996). It is a light-demanding and fast-growing tree species. Nuts and burrs are mainly dispersed by animals (especially squirrels, mice, wild boars, and bears) and gravity. This species is threatened by selective logging for its timber.

\section{Sampling design}

A provisional forest cover map was established based on a reconnaissance survey. Land at an elevation of $1000 \mathrm{~m}$ to $1700 \mathrm{~m}$ a.s.l. was selected for the study, as forest occurred in all three conservation zones within this range. The study area consisted of 73 ha in the core zone, 115 ha in the buffer zone and 22 ha in the restoration zone. A grid system with 1400 cells was created and overlaid on the study area to randomly place the sample plots. Forty plots of $20 \mathrm{~m} \times 20 \mathrm{~m}$ were established in each conservation zone, with the center of each plot located in the center of a selected cell (Dao et al. 2016).

Adaptive cluster sampling (ACS) initially uses randomly located plots, then successively adds plots close to those having a target species. Any additional plots having the species have more neighboring plots added, leading to a cluster of plots. This method is particularly suitable for finding trees and effective if the population of interest species is rare and clustered (Thompson 1990). The method leads to an unbiased estimate of mean abundance via the HansenHurwitz estimator (Thompson and Seber 1996). The 40 random sample plots of $400 \mathrm{~m}^{2}(20 \mathrm{~m} \times 20 \mathrm{~m})$ per conservation zone were the initial plots. This procedure was applied separately for each of the three target species with a focus on big trees with a diameter at breast height $(\mathrm{DBH})$ of at least $6 \mathrm{~cm}$ $\left(\right.$ tree $\left._{\geq 6 \mathrm{~cm}}\right)$. The final number of established plots is presented in Table 1.
For the inventory of tree regeneration $(\mathrm{DBH}<6 \mathrm{~cm})$, in the center of each initial random plot and also in additional ACS plots, a subplot of $25 \mathrm{~m}^{2}(5 \mathrm{~m} \times 5 \mathrm{~m})$ was established.

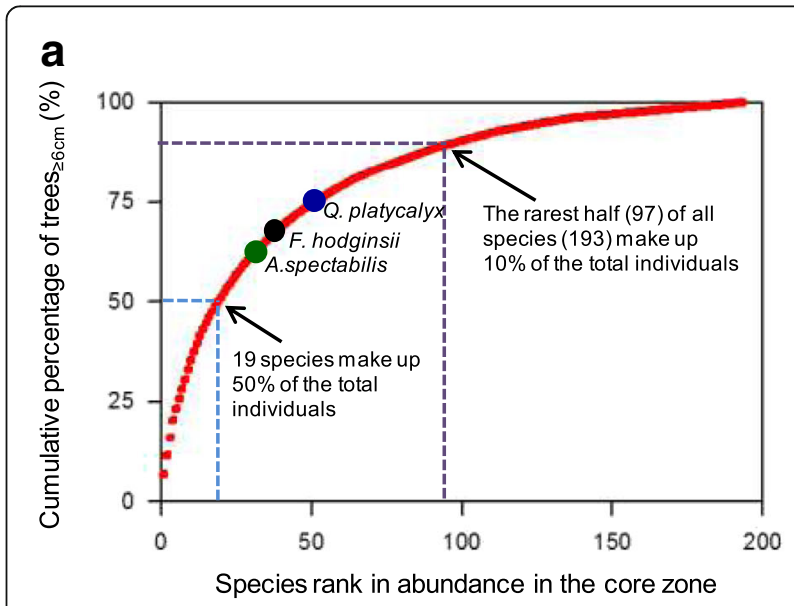

b

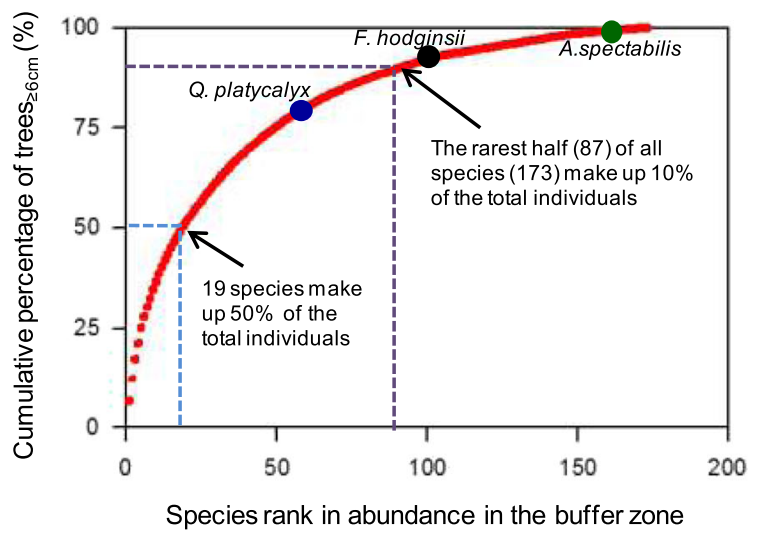

C

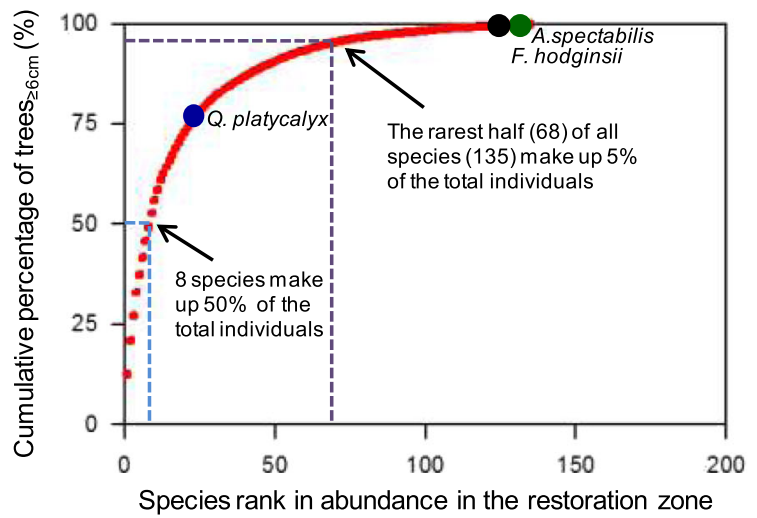

Fig. 3 Cumulative abundance of tree species (trees $\geq 6 \mathrm{~cm}$ ) in 40 initial random plots in the core zone (a, 193 species), buffer zone (b, 173 species), and restoration zone (c, 133 species). The ordinate represents the cumulative percentage of individuals, and the abscissa represents the abundance rank of species, from most abundant (left) to rarest (right). The rank abundance of the three target species is indicated 


\section{Data collection}

Field work was conducted in 2014. In the initial and adaptively added plots, each target and non-target tree ${ }_{\geq 6 \mathrm{~cm}}$ was counted, and its DBH was measured. All trees ${ }_{\geq 6 \mathrm{~cm}}$ in the $400 \mathrm{~m}^{2}$ plots, and regenerating trees ${ }_{<6 \mathrm{~cm}}$ in subplots of $25 \mathrm{~m}^{2}$ were identified at the species level, with assistance from two botanists of the Vietnam National University of Forestry (VNUF). Field specimens of unidentified non-target species were collected for identification using the herbarium of the VNUF. Non-target trees that could not be identified at species level were classified by genus or family, and sorted into morphospecies. Some information about site conditions including elevation, slope inclination and soil $\mathrm{pH}$, forest structure characteristics such as canopy closure, tree density and basal area, and human interference (numbers of stumps and footpaths) in the initial random sample plots was also collected.

The three conservation zones had similar basic site characteristics such as soil $\mathrm{pH}$ and slope inclination (Table 2). The two signs of human disturbance, number of stumps and number of footpaths, were lowest in the core zone; the greatest number of footpaths was in the buffer zone and the greatest number of stumps was in the restoration zone (Dao and Hölscher 2015).

\section{Statistical analysis}

An ANOVA was used to determine the significance of differences in the means of the three conservation zones (significant if $p \leq 0.05$ ) if the data satisfied the criteria of normal distribution and equality of the variances. When these requirements were not met, the non-parametric Kruskal-Wallis $H$ test was applied. The mean densities of the three target species from adaptive cluster sampling were calculated using the modified and unbiased Hansen-Hurwitz estimator (Thompson and Seber 1996). The total population sizes of the three target tree species (trees ${ }_{\geq 6 \mathrm{~cm}}$ ) in each conservation zone were estimated based on the average densities as derived from the adaptive cluster sampling, total area of the zone and percentages of forest cover in the respective zone.

\section{Results}

\section{Abundance of the three target species}

In the core zone, the three target species were moderately rare tree species. The abundance ranks of $F$. hodginsii, $A$. spectabilis and Q. platycalyx were 34,32 and 49 , respectively (Fig. 3a). The average density of $F$. hodginsii was 4.9 trees.ha ${ }^{-1}$; A. spectabilis was 5.1 trees $\cdot \mathrm{ha}^{-1}$, and Q. platycalyx was 4.4 trees.ha $^{-1}$ (Table 1). F. hodginsii and A. spectabilis were much less abundant in the buffer and restoration zones; however, Q. platycalyx had its highest density in the restoration zone (Table 1, Fig. 3b \& c).

A rough estimation of the total population sizes of $F$. hodginsii, A. spectabilis and Q. platycalyx (trees $\geq 6 \mathrm{~cm}$ ) results in $64,844,67,491$ and 58,228 trees $_{\geq 6 \mathrm{~cm}}$, in the core zone, respectively; 20,627, 6,513 and 53,197 trees $_{\geq 6 \mathrm{~cm}}$ in the buffer zone; and 834, 834, 23,078 trees $_{\geq 6 \mathrm{~cm}}$ in the restoration zone.

\section{Regeneration}

We examined 40 random subplots of $25 \mathrm{~m}^{2}$ to assess tree regeneration. There were 133 regenerating tree species in the core zone, 130 in the buffer zone, and 80 in the restoration zone. The highest density of regeneration of all tree species was in the core zone, and the lowest density was in the restoration zone (Table 3 ).

Our random sampling method indicated regeneration of the three target species in the core zone. However, there was no regeneration of $F$. hodginsii in the buffer zone and no regeneration of $A$. spectabilis in the restoration zone (Table 3 and Fig. 4).

Regeneration was also assessed in the subplots of the adaptive cluster sampling plots. In the core zone, these subplots had 17 regenerating $F$. hodginsii trees and 52 regenerating $A$. spectabilis trees. None of the subplots inside the added negative plots - which had no target trees $\geq 6 \mathrm{~cm}$ - had any regenerating trees of F. hodginsii and A. spectabilis (Table 4). For $Q$.

Table 3 Species richness and density of regenerating tree species in the three conservation zones. The results are from 40 initial random subplots per zone

\begin{tabular}{|c|c|c|c|}
\hline & Core zone & Buffer zone & Restoration zone \\
\hline Observed species richness (trees $<6 \mathrm{~cm}, \mathrm{sp}$. per 40 subplots) & 133 & 130 & 80 \\
\hline Tree density $\left(\right.$ trees $_{<6 \mathrm{~cm}} \cdot$ subplots $^{-1}$ ) & $31.9 \pm 22.6^{\mathrm{a}}$ & $24.7 \pm 16.6^{\mathrm{ab}}$ & $22.2 \pm 12.1^{b}$ \\
\hline $\begin{array}{l}\text { F. hodginsii (trees }<6 \mathrm{~cm} \text {. } \\
(40 \text { subplots })^{-1} \text { ) }\end{array}$ & 2 & 0 & 2 \\
\hline $\begin{array}{l}\text { A. spectabilis (trees }<6 \mathrm{~cm} \text {. } \\
\left.(40 \text { subplots })^{-1}\right)\end{array}$ & 2 & 2 & 0 \\
\hline $\begin{array}{l}\text { Q. platycalyx }\left(\text { trees }_{<6 \mathrm{~cm}}\right. \\
\left.(40 \text { subplots })^{-1}\right)\end{array}$ & 7 & 1 & 3 \\
\hline
\end{tabular}

Significant differences in tree density of three zones at the level of $p \leq 0.05$ were indicated in different superscript letters. Numbers are means and standard deviations 


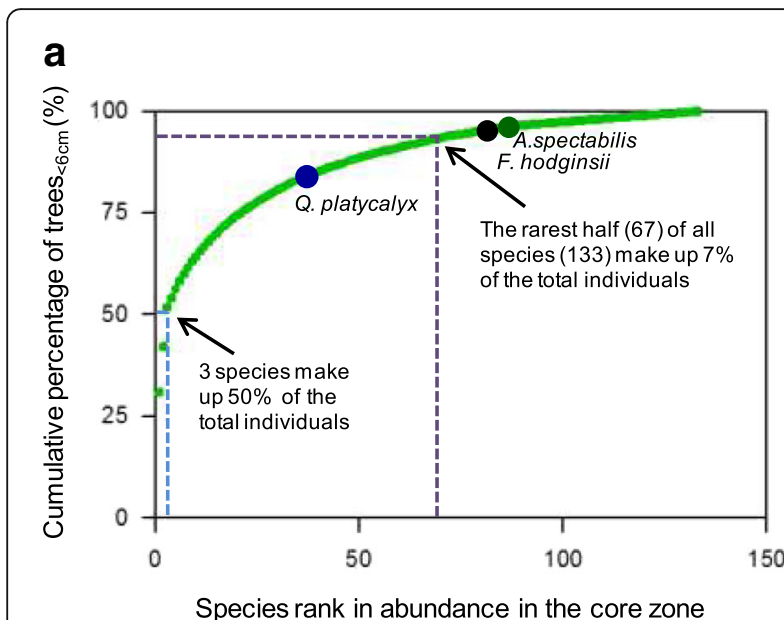

b

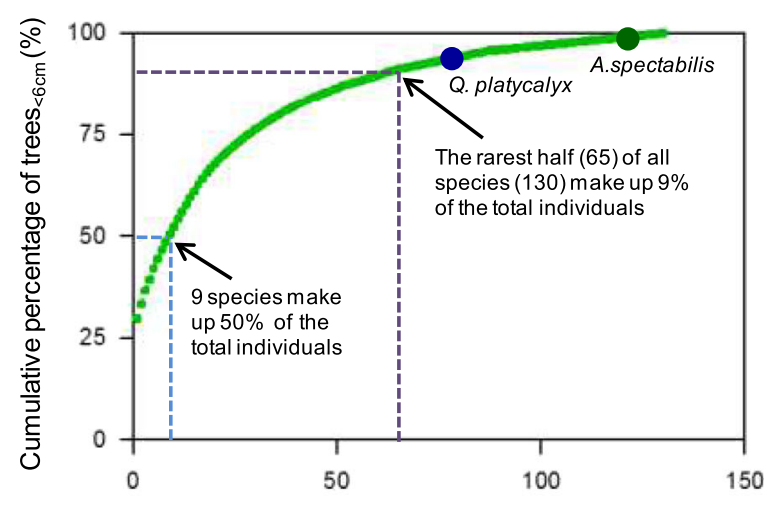

Species rank in abundance in the buffer zone

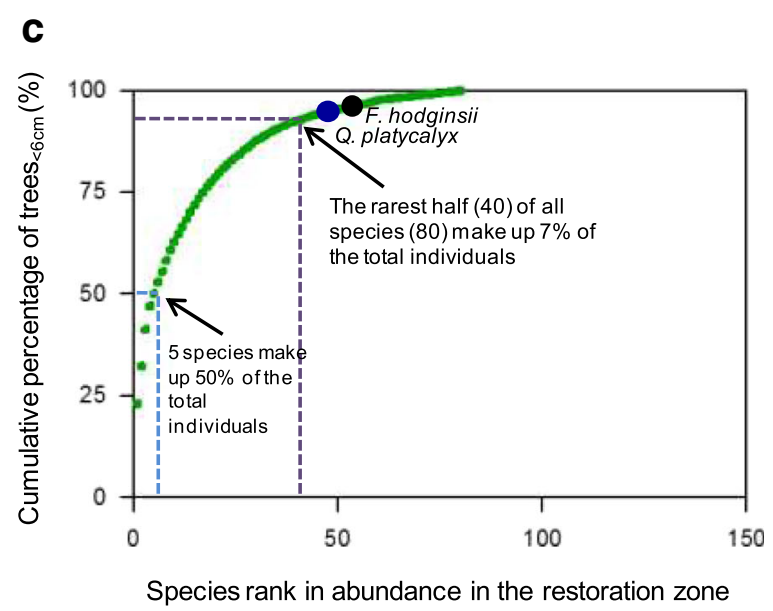

Fig. 4 Cumulative abundance of regenerating tree species (trees $\left.{ }_{66 \mathrm{~cm}}\right)$ in 40 initial random subplots in the core zone $(\mathbf{a}, 133$ species), buffer zone (b, 130 species), and restoration zone (c, 80 species). The ordinate represents the cumulative percentage of individuals, and the abscissa represents the abundance rank of species, from most abundant (left) to rarest (right). The rank abundance of the three target species is indicated. Note, there were no regenerating $F$. hodginsii trees in the buffer zone (b), and no regenerating $A$. spectabilis trees in the restoration zone (c) platycalyx, the four initial sample subplots had 7 regenerating trees, but no more regenerating trees were detected in subplots inside added positive and added negative plots. In the buffer zone, we observed no regenerating trees of $F$. hodginsii in any of the added subplots, and in the restoration zone only one regenerating tree of $A$. spectabilis was observed. These results indicate that regenerating trees of $F$. hodginsii and $A$. spectabilis often appeared in the vicinity of large conspecifics in the core zone.

\section{Discussion}

Our study indicates that the abundance of $F$. hodginsii and $A$. spectabilis was highest in the core zone, and much lower in the buffer and restoration zones. In contrast, the abundance of $Q$. platycalyx was greatest in the restoration zone. We found regeneration of all three target species in the core zone; however, a small number of regeneration individuals of $F$. hodginsii and $A$. spectabilis was found in the buffer and restoration zones. F. hodginsii and A. spectabilis had aggregated distributions, and regenerating trees of these species were mostly near large conspecific trees in the core zone.

The greatest density of $F$. hodginsii was found in the core zone. Densities were much lower in the buffer and restoration zones. The mature trees had a highly aggregated distribution in the strictly protected core zone. This finding is in line with the results of a study of $F$. hodginsii in Chu Yang Sin National Park, in the Central Highlands of Vietnam (Dang 2010). In that previous study distances were measured from specific individuals to their nearest neighbors using the Clark and Evans (1954) index of aggregation. The results indicated that $F$. hodginsii occurred in a clumped distribution. In Vietnam, the main reason for the declining population of $F$. hodginsii is overexploitation because of the valuable timber of this species (Luu and Thomas 2004; Farjon 2010). Mature F. hodginsii trees have been heavily harvested by legal and illegal logging over the past 50 years (Nguyen et al. 2015). Although many recent laws protect and limit the use of this species' timber (Osborn 2004), the number of mature trees is still declining. For example, F. hodginsii is currently one of the most exploited species in the Hoang Lien - Van Ban Nature Reserve (Lam and Yen 2013).

Regenerating $F$. hodginsii trees were most abundant in the core zone; however, there were only a few regenerating individuals in the buffer zone and the restoration zone. Intensive logging of large-diameter trees may have led to insufficiency of seeds for natural regeneration and low seedling densities in the logged forests (Plumptre 1995). Furthermore, some biological attributes of $F$. hodginsii seeds, such as a low germination rate (30-360 days), and a relatively hard seed coat (Nguyen et al. 2015), may have also contributed to the poor regeneration. 
Table 4 Number of initially positive subplots for regenerating trees $<6 \mathrm{~cm}$ (among 40 initial random subplots per zone); subplots and trees $_{<6 \mathrm{~cm}}$ in added positive plots and added negative plots (from ACS of trees $\geq 6 \mathrm{~cm}$ ), and total detected trees $<6 \mathrm{~cm}$ of three target species

\begin{tabular}{|c|c|c|c|c|c|c|c|c|}
\hline & \multirow{3}{*}{$\begin{array}{l}\text { Conservation } \\
\text { zone }\end{array}$} & \multicolumn{2}{|c|}{ Random sampling } & \multicolumn{4}{|c|}{ ACS added plots base on trees $\geq 6 \mathrm{~cm}$} & \multirow{3}{*}{$\begin{array}{l}\text { Total } \\
\text { detected } \\
\text { tree }<6 \mathrm{~cm}\end{array}$} \\
\hline & & \multirow{2}{*}{$\begin{array}{l}\text { Positive } \\
\text { subplot }\end{array}$} & \multirow[t]{2}{*}{ Tree $_{<6 \mathrm{~cm}}$} & \multicolumn{2}{|c|}{ Subplots in added plots } & \multicolumn{2}{|c|}{ Subplots in added negative plots } & \\
\hline & & & & Subplot & Tree $_{<6 \mathrm{~cm}}$ & Subplot & Tree $_{<6 \mathrm{~cm}}$ & \\
\hline \multirow[t]{3}{*}{ F. hodginsii } & Core & 1 & 2 & 7 & 17 & 31 & 0 & 19 \\
\hline & Buffer & 0 & 0 & 0 & 0 & 4 & 0 & 0 \\
\hline & Restoration & 2 & 2 & 0 & 0 & 4 & 0 & 2 \\
\hline \multirow[t]{3}{*}{ A. spectabilis } & Core & 2 & 2 & 23 & 52 & 53 & 0 & 54 \\
\hline & Buffer & 2 & 2 & 0 & 0 & 4 & 0 & 2 \\
\hline & Restoration & 0 & 0 & 1 & 1 & 6 & 0 & 1 \\
\hline \multirow[t]{3}{*}{ Q. platycalyx } & Core & 4 & 7 & 0 & 0 & 38 & 0 & 7 \\
\hline & Buffer & 1 & 1 & 3 & 4 & 31 & 0 & 5 \\
\hline & Restoration & 2 & 3 & 0 & 0 & 18 & 0 & 3 \\
\hline
\end{tabular}

In this study, we only found seedlings of $F$. hodginsii in the vicinity of conspecific adult trees in the core zone. In general, the Janzen-Connell hypothesis (Janzen 1970; Connell 1971) postulates that host-specific pests may reduce recruitment near reproductive adults. Findings from other studies also supported the negative density dependence that constrains juvenile performance near reproducing conspecifics (Comita et al. 2014). However, the same does not seem to apply to F. hodginsii. Hubbell (1979) and Hubbell and Foster (1983) previously reported that roughly half of the tree species in dry and moist neotropical forests germinate in dense aggregations beneath their parents. The study in Chu Yang Sin National Park (Dang 2010) also found regenerating $F$. hodginsii trees only near mature conspecifics. The greater seed density beneath the parent trees and a favorable microhabitat for germination and seedling survival (Wright 2002; Crawley 2009) may explain the presence of regenerating trees near parents in the core zone. In the case of $F$. hodginsii chemical exudates from the adult trees may also support the survival of juveniles near mature trees. Several studies indicated that the essential oils of $F$. hodginsii are rich in sesquiterpenes with strong defence mechanisms against mosquitoes and other insects (Lesueur et al. 2006; Paluch 2009). However, only a limited number of previous studies did examine the spatial distribution of regenerating F. hodginsii trees. The spatial pattern of regenerating and adult $F$. hodginsii trees requires therefore more rigorous analysis, otherwise the ecological reasons for the aggregated distributions remain speculative. Our results, however, clearly show that adult and regenerating $F$. hodginsii trees are mainly confined to the core zone, making that zone an important refuge for this species.

The distribution pattern of $A$. spectabilis is similar to that of $F$. hodginsii. In particular, most trees were observed in clusters in the core zone, but a few occurred in the buffer and restoration zones. In addition, many regenerating trees were concentrated near conspecific adults in the core zone, but regenerating trees were very rare in the buffer and restoration zones. Our results indicate that $A$. spectabilis is an endangered tree species, and the core zone is important for its persistence.

The distribution patterns of Q. platycalyx was very different when compared to those of $F$. hodginsii and $A$. spectabilis. The greatest number of individuals was found in the restoration zone, a moderate number occurred in the buffer zone, and the lowest number occurred in the core zone. Regenerating $Q$. platycalyx trees were present in all three conservation zones, although their numbers were low and their distribution was scattered. In our study area, the restoration zone was disturbed by previous shifting cultivation, so it is evident that $Q$. platycalyx is able to colonize disturbed sites. Q. platycalyx is likely to be one of the species occupying early successional habitats and has good regeneration after coppicing (Nguyen et al. 1996; Le and Le 2000).

\section{Conclusion}

Our results indicate that $F$. hodginsii and $A$. spectabilis were mostly confined to the core zone, and regeneration of these species was rare in the buffer and restoration zones. For these two species, the protected core zone was the most important refuge. Continued conservation of this zone is therefore essential to ensure the preservation of these rare and important species. The high occurrence of Q. platycalyx in the Ta Xua Nature Reserve does not confirm the need to classify this species as 'vulnerable' in the Vietnam Red List. This study, which is based on a one-time census, should be complemented by future research initiatives that will investigate population dynamics. Forest monitoring with repeated population assessments is needed to estimate the vulnerability and long-term survival of a threatened tree species. 


\section{Appendix}

Table 5 Rank abundance of the most common tree species that account for $50 \%$ of total individuals in each conservation zone

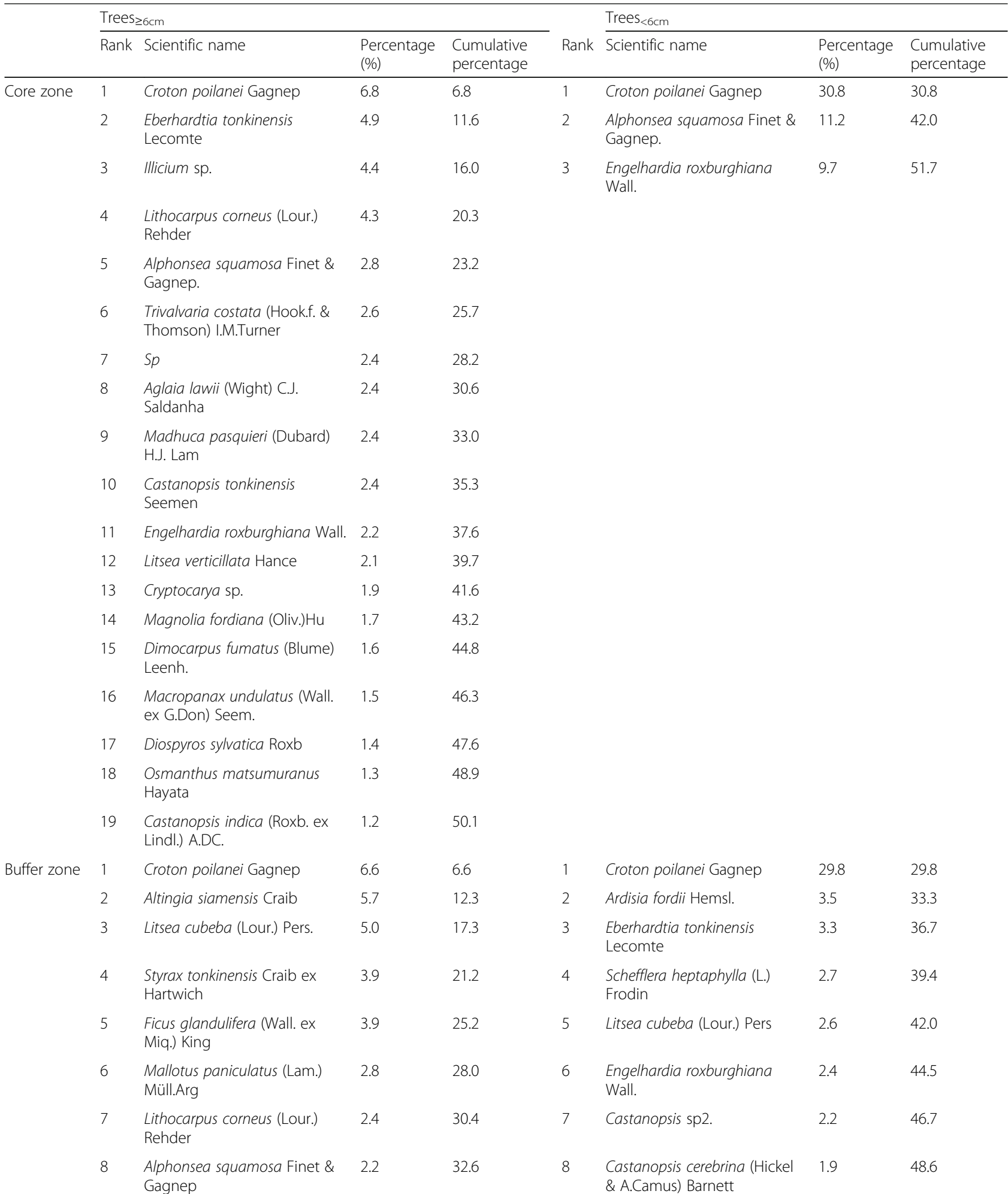


Table 5 Rank abundance of the most common tree species that account for $50 \%$ of total individuals in each conservation zone (Continued)

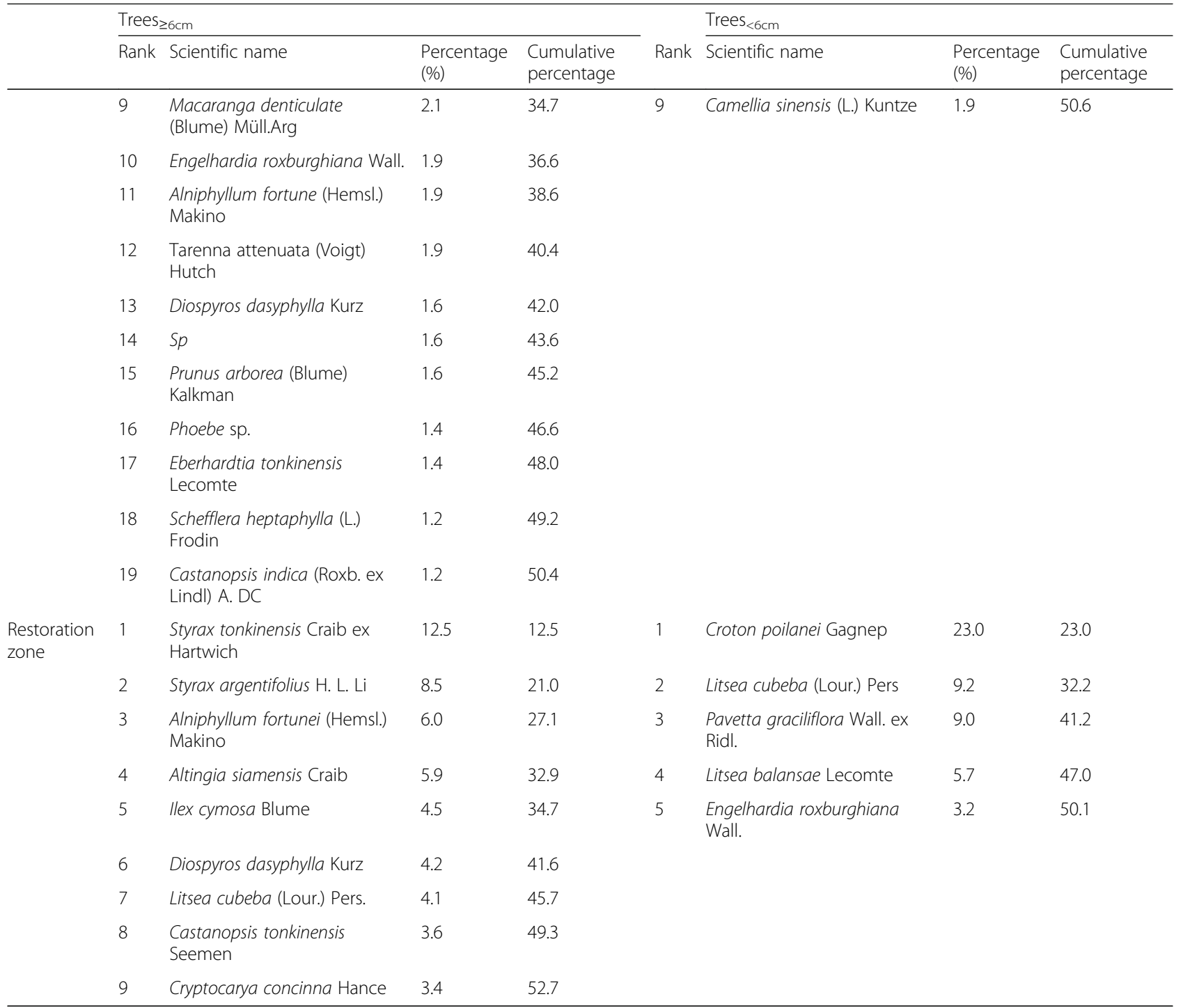

\section{Acknowledgments}

We thank Nguyen Q.D., Luong V.P., Luong V.T., Dang V.L., Dao V.P., Nguyen M.T., Pham K.C., Vang A.S., and Vang A.C. for their assistance during different phases of the fieldwork; the two botanists, Trinh N.B. and Phan V.D., for tree identification; Tran T.H. and Nguyen T.H. for help in soil sample analysis; Dr. Ngo T.L., Dr. Peque D., Phan T.N., and Le T.K. for their comments on our research; and the managers and local people in the Ta Xua Nature Reverse for helping us conduct this study. We also thank the anonymous reviewers and the editor for their valuable comments on earlier versions of the manuscript.

\section{Funding}

This study was supported by the Vietnamese Government, the German Academic Exchange Service (DAAD), and the Rufford Small Grants Foundation.

\section{Authors' contributions}

The first author collected data, performed the data analysis and wrote the manuscript. The second author conceived the study, provided guidance and reviewed the manuscript. Both authors read and approved the final manuscript.

\section{Competing interests}

The authors declare that they have no competing interests.

Received: 2 January 2017 Accepted: 27 November 2017

Published online: 18 December 2017

\section{References}

Bruner AG, Gullison RE, Rice RE, da Fonseca GAB (2001) Effectiveness of parks in protecting tropical biodiversity. Science 291:125-128. https://doi.org/10.1126/ science.291.5501.125

Chape S, Harrison J, Spalding M, Lysenko I (2005) Measuring the extent and effectiveness of protected areas as an indicator for meeting global biodiversity targets. Phil Trans R Soc B 360(1454):443-455. https://doi.org/10. 1098/rstb.2004.1592

Clark PJ, Evans FC (1954) Distance to nearest neighbor as a measure of spatial relationships in populations. Ecology 35(4):445-453. https://doi.org/10.2307/ 1931034

Cochran WG (1977) Sampling techniques. Wiley, New York

Comita LS, Queenborough SA, Murphy SJ, Eck JL, Xu K, Krishnadas M, Beckman N, Zhu Y (2014) Testing predictions of the Janzen-Connell hypothesis: a meta-analysis of experimental evidence for distance-and density-dependent 
seed and seedling survival. J Ecol 102(4):845-856. https://doi.org/10.1111/ $1365-2745.12232$

Connell JH (1971) On the role of natural enemies in preventing competitive exclusion in some marine animals and in rain forest trees. In: den Boer PJ, Gradwell GR (eds) Dynamics of populations, proceedings of the advanced study institute on dynamics of numbers in populations, Oosterbeek, 1970. Cent Agric Publ Doc, Wageningen, Netherlands, pp 298-312

Crawley MJ (2009) Plant-herbivore dynamics. In: Crawley MJ (ed) Plant Ecology, 2nd edn. Blackwell, London, p 401-474

Dang HP (2010) Determining ecological factors affecting the distribution and regeneration of Fokienia hodginsii in Chu Yang Sin National Park, Central Highlands of Vietnam. (master's thesis). University of Tay Nguyen, Vietnam

Dao THH, Hölscher D (2015) Red-listed tree species abundance in montane forest areas with differing levels of statutory protection in north-western Vietnam. Trop Conserv Sci 8(2):479-490

Dao THH, Saborowski J, Hölscher D (2016) Patterns of tree community differences in the core and buffer zones of a nature reserve in north-western Vietnam. Glob Ecol Conserv 8:220-229. https://doi.org/10.1016/j.gecco.2016.09.011

DeFries R, Hansen A, Newton AC, Hansen MC (2005) Increasing isolation of protected areas in tropical forests over the past twenty years. Ecol Appl 15(1):19-26. https://doi.org/10.1890/03-5258

Dirzo R, Raven PH (2003) Global state of biodiversity and loss. Annu Rev Environ Resour 28:137-167. https://doi.org/10.1146/annurev.energy.28.050302.105532

Facelli JM, Pickett STA (1991) Plant litter: its dynamics and effects on plant community structure. Bot Rev 57(1):1-32. https://doi.org/10.1007/BF02858763

Farjon A (2010) A Handbook of the World's Conifers. Brill Academic Publishers, Leiden, p 983-985

Fearnside PM (1997) Protection of mahogany: a catalytic species in the destruction of rain forests in the American tropics. Environ Conserv 24(4):303-306

Forest Inventory and Planning Institute (FIPI) (2002) Project of conservation and development forest resources of Ta Xua Nature Reserve. Hanoi (Unpublished report)

Gaston KJ (1994). Rarity. New York: Springer Publishing. doi: 10.1007/978-94-0110701-3

Gibson L, Lee TM, Koh LP, Brook BW, Gardner TA, Barlow J, Peres CA, Bradshaw CJ, Laurance WF, Lovejoy TE (2011) Primary forests are irreplaceable for sustaining tropical biodiversity. Nature 478:378-381. https://doi.org/10.1038/nature 10425

Hubbell SP (1979) Tree dispersion, abundance, and diversity in a tropical dry forest. Science 203:1299-1309. https://doi.org/10.1126/science.203.4387.1299

Hubbell SP (2013) Tropical rain forest conservation and the twin challenges of diversity and rarity. Ecol Evol 3(10):3263-3274. https:/doi.org/10.1002/ece3.705

Hubbell SP, Foster RB (1983) Diversity of canopy trees in a neotropical forest. In Tropical Rain Forest: Ecology and Management, Sutton SL, Whitmore TC, Chadwick AC (eds), 25-42. Br. Ecol. Soc., Spec. Publ. No. 2. Blackwell, Oxford

IUCN (2014) The IUCN Red List of Threatened Species. Version 2014.3. http:// www.iucnredlist.org. Accessed 21 Nov 2014

Janzen DH (1970) Herbivores and the number of tree species in tropical forests. Am Nat 104:501-528

Joppa LN, Pfaff A (2010) Global protected area impacts. Proc R Soc B. https://doi. org/10.1098/rspb.2010.1713

Lam HV, Yen HM (2013) Hoang Lien-Van Ban Nature Reserve. In: Evidence-based conservation: lessons from the lower Mekong. Earthscan, London

Laurance WF (1999) Reflections on the tropical deforestation crisis. Biol Conserv 91:109-117 doi: 10. 1016/S0006-3207(99)00088-9

Law No.29/2004/QH 11 (2004) Protection and development of forest, the National Assembly of the Socialist Republic of Vietnam

Le MC, Le TH (2000) Forest plants. Agricultural Publishing House, Hanoi

Lesueur D, Ban NK, Bighelli A, Muselli A, Casanova J (2006) Analysis of the root oil of Fokienia hodginsii (Dunn) Henry et Thomas (Cupressaceae) by GC, GC-MS and 13C-NMR. Flavour Frag J 21(1):171-174. https://doi.org/10.1002/ffj.1557

Luu NDT, Thomas PI (2004) Conifers of Vietnam: an illustrated field guide. World Publishing House, Hanoi

Nguyen DQ, Phan TPH, Dao VT (2015) Effect of storage time and pretreatment on seed germination of the threatened coniferous species Fokienia hodginsii. Plant Species Biol 30(4):291-296. https://doi.org/10.1111/1442-1984.12062

Nguyen HN (2000) Some threatened tree species of Vietnam. Agricultural Publishing House, Hanoi

Nguyen NC, Cao TC, Vu VC, Nguyen XD, Vu VD, Nguyen KD, Tran H, Tran TO, Nguyen BQ, Nguyen NT (1996) Vietnam forest trees. Agricultural Publishing House, Hanoi Nguyen TB, Tran DL, Nguyen KK (2007) Vietnam red list. Part II: plants. Science and Techniques Publishing House, Hanoi
Osborn T (2004) Preparation and implementation of a strategy for the management of Fokienia hodginsii in Vietnam by 2008. A desk study for the Hoang Lien son project, Fauna and Flora International Vietnam

Paluch GE (2009) Characterization of botanical terpene activity in arthropods (Doctoral dissertation), lowa State University, USA. Retrieved from http://lib.dr. iastate.edu/

Philippi T (2005) Adaptive cluster sampling for estimation of abundances within local populations of low-abundance plants. Ecology 86(5):1091-1100 http:// www.jstor.org/stable/3450870

Plumptre AJ (1995) The importance of "seed trees" for the natural regeneration of selectively logged tropical forest. Commonwealth For Rev 74(3):253-258 http://www.jstor.org/stable/42608376

Sodhi NS, Koh LP, Brook BW, Ng PK (2004) Southeast Asian biodiversity: an impending disaster. Trends Ecol Evol 19(12):654-660. https://doi.org/10.1016/ j.tree.2004.09.006

Sodhi NS, Koh LP, Clements R, Wanger TC, Hill JK, Hamer KC, Clough Y, Tscharntke T, Posa MRC, Lee TM (2010) Conserving southeast Asian forest biodiversity in human-modified landscapes. Biol Conserv 143(10):2375-2384. https://doi.org/10.1016/j.biocon.2009.12.029

Sodhi NS, Lee TM, Koh LP, Brook BW (2009) A meta-analysis of the impact of anthropogenic Forest disturbance on Southeast Asia's Biotas. Biotropica 41(1):103-109. https://doi.org/10.1111/j.1744-7429.2008.00460.x

ter Steege H, Pitman NC, Sabatier D, Baraloto C, Salomão RP, Guevara JE, Phillips OL, Castilho CV, Magnusson WE, Molino JF (2013) Hyperdominance in the Amazonian tree flora. Science 342:1243092. https://doi.org/10.1126/science.1243092

Thai VT (1998) Ecosystem of tropical forests in Vietnam. Science and Technique Publishing House, Hanoi

Thomas P, Yang Y (2013) Fokienia hodginsii. The IUCN Red List of Threatened Species 2013. https://doi.org/10.2305/IUCN.UK.2013-1.RLTS.T32351A2815809.en

Thompson SK (1990) Adaptive cluster sampling. J Am Stat Assoc 85(412):1050-1059

Thompson SK, Seber GAF (1996) Adaptive sampling. Wiley, New York

Williams PH, Burgess ND, Rahbek C (2000) Flagship species, ecological complementarity and conserving the diversity of mammals and birds in subSaharan Africa. Anim Conserv 3(3):249-260

Wright JS (2002) Plant diversity in tropical forests: a review of mechanisms of species coexistence. Oecologia 130(1):1-14. https://doi.org/10.1007/ s004420100809

\section{Submit your manuscript to a SpringerOpen ${ }^{\circ}$ journal and benefit from:}

- Convenient online submission

- Rigorous peer review

- Open access: articles freely available online

- High visibility within the field

Retaining the copyright to your article

Submit your next manuscript at $>$ springeropen.com 